This is the author's final, peer-reviewed manuscript as accepted for publication. The publisher-formatted version may be available through the publisher's web site or your institution's library.

\title{
From Asian curiosity to eruptive American pest: Megacopta cribraria (Hemiptera: Plataspidae) and prospects for its biological control
}

John R. Ruberson, Keiji Takasu, G. David Buntin, Joe E. Eger, Jr., Wayne A. Gardner, Jeremy K. Greene, Tracie M. Jenkins, Walker A. Jones, Dawn M. Olson, Phillip M.

Roberts, Daniel R. Suiter, Michael D. Toews

\section{How to cite this manuscript}

If you make reference to this version of the manuscript, use the following information:

Ruberson, J. R., Takasu, K., Buntin, G. D., Eger, J. E., Gardner, W. A., Greene, J. K., ... Toews, M. D. (2013). From Asian curiosity to eruptive American pest: Megacopta cribraria (Hemiptera: Plataspidae) and prospects for its biological control. Retrieved from http://krex/ksu/edu

\section{Published Version Information}

Citation: Ruberson, J. R., Takasu, K., Buntin, G. D., Eger, J. E., Gardner, W. A., Greene, J. K., ... Toews, M. D. (2013). From Asian curiosity to eruptive American pest: Megacopta cribraria (Hemiptera: Plataspidae) and prospects for its biological control. Applied Entomology and Zoology, 48(1), 3-13.

Copyright: (C) The Japanese Society of Applied Entomology and Zoology 2012

Digital Object Identifier (DOI): doi:10.1007/s13355-012-0146-2

Publisher's Link: http://link.springer.com/article/10.1007/s13355-012-0146-2

This item was retrieved from the K-State Research Exchange (K-REx), the institutional repository of Kansas State University. K-REx is available at http://krex.ksu.edu 
From Asian Curiosity to Eruptive American Pest: Megacopta CRibraria (Hemiptera: Plataspidae) and

\section{Prospects for Its Biological Control}

John R. Ruberson ${ }^{1}$, Keiji Takasu², G. David Buntin ${ }^{3}$, Joe E. Eger, Jr. ${ }^{4}$, Wayne A. Gardner ${ }^{3}$, Jeremy K. Greene ${ }^{5}$, Tracie M. Jenkins ${ }^{3}$, Walker A. Jones ${ }^{6}$, Dawn M. Olson ${ }^{7}$, Phillip M. Roberts ${ }^{1}$, Daniel R. Suiter ${ }^{3}$, Michael D. Toews ${ }^{1}$

${ }^{1}$ Department of Entomology, University of Georgia, 2360 Rainwater Road, Tifton, GA 31793, USA; *Current address: Department of Entomology, Kansas State University, 123 Waters Hall, Manhattan, KS 66506, USA

${ }^{2}$ Faculty of Agriculture, Kyushu University, Fukuoka 812-8581, Japan

${ }^{3}$ Department of Entomology, University of Georgia, 1109 Experiment St., Griffin, GA 30223, USA

${ }^{4}$ Dow AgroSciences, 2606 S. Dundee St., Tampa, FL 33629, USA

${ }^{5}$ School of Agricultural, Forest, and Environmental Sciences, Clemson University, Edisto Research and Education Center, 64 Research Road, Blackville, SC 29817

${ }^{6}$ USDA-ARS, Biological Control of Pests and National Biological Control Laboratory, Stoneville, MS 38776, USA

${ }^{7}$ USDA-ARS, Crop Protection and Management Research Unit, P.O. Box 748, Tifton GA 31793, USA 
Corresponding author: John R. Ruberson (ruberson@uga.edu): Department of Entomology,

University of Georgia, 2360 Rainwater Road, Tifton, GA 31793; Phone: 01-229-386-7251;

Fax: 01-229-386-3086 


\begin{abstract}
The kudzu bug or bean plataspid, Megacopta cribraria (Fabricius), is native to Asia where it appears to be widely distributed (although the taxonomy is not entirely clear), but is infrequently a pest of legumes. This bug appeared in 2009 in the southeastern United States, where it is closely associated with kudzu, Pueraria montana Lour. [Merr.] variety lobata [Willd.] Maesen \& S. Almeida. However, the insect has become a consistent economic pest of soybeans, Glycine $\max ($ L.) Merr., and some other leguminous crops in areas where large numbers can build in kudzu, in addition to being a considerable nuisance in urban landscapes where kudzu occurs. The insect has remarkable capacity for movement, and has spread rapidly from nine Georgia counties in 2009 to seven states in 2012. Despite being a nuisance in urban areas and a crop pest, high populations of the bug also reduce the biomass of kudzu, which is itself a seriously problematic invasive weed, complicating the status of $M$. cribraria in its expanded range. Extant predators and a pathogen in the US have been observed attacking kudzu bugs in the laboratory and field, but no parasitism of eggs or nymphs has been observed to date. A single record of parasitism of an adult kudzu bug by a tachinid fly is known from the US, but no other adult parasitism has been observed in the US or elsewhere. Extant enemies may eventually significantly reduce the bug's populations, but at present native enemies appear to be insufficient for the task, and exotic enemies from the kudzu bug's native range may offer the best possibility for effective biological control in the US. Based on the available literature, the best option for an importation biological control program appears to be the platygastrid egg parasitoid Paratelenomus saccharalis (Dodd) because of its apparent host specificity, intimate biological linkages with $M$. cribraria, and wide geographic distribution in the Eastern
\end{abstract}


Hemisphere. Other natural enemies may eventually emerge as good candidates for importation, but at present $P$. saccharalis appears to be most promising.

Keywords: Kudzu bug, Bean plataspid, Globular stink bug, biological control, invasive species 


\section{INTRODUCTION}

2 The bean plataspid or kudzu bug, Megacopta cribraria (Fabricius), made its first known

3

4 appearance in the Western Hemisphere in fall of 2009, when it was reported aggregating in large numbers on and around homes in urban areas of northern Georgia near Atlanta (see review of discovery in Suiter et al. 2010). These homes were associated with patches of kudzu, Pueraria montana var. lobata (Willd.) Maesen \& S. Almeida, where large numbers of the bug were observed. The kudzu bug was initially identified by Dr. Joe Eger (Dow AgroSciences) following collections by Dr. Daniel Suiter (University of Georgia). Working with Drs. Eger and Suiter, Dr. Tracie Jenkins soon added a 2336 bp mitochondrial DNA (mtDNA) marker (GenBank \# HQ444175) (Jenkins and Eaton 2011). This established a one-to-one correlation between morphology and DNA early in the history of this bugs invasion, and it established a genetic marker that could be used to track country of origin, port of entry, study maternal genetic diversity and evaluate genetic change over time. Because kudzu is so abundant in the region and it supports very large populations of $M$. cribraria, kudzu and the kudzu bug have generated a serious pest problem that includes high numbers of insects flying about and landing on homes and people. The malodorous bugs also produce a yellow substance when crushed that can stain cloth and wood, and nymphs, in particular, can cause welts and inflammation on skin. These issues, and the possible threat to soybeans in the region, triggered an effort to obtain biological information on the bug and its enemies in its native range. The purpose of this review is to summarize the information available on the insect in the US and in its native range relevant to its activity in North America and to provide current information on its status in North America and the prospects for biological control. 


\section{Biology of Megacopta CRibraria ANd Pest Status}

We have chosen to consider the species occurring in the southeastern United States as $M$. cribraria although we recognize that there is some uncertainty in the identity of this species. Eger et al. (2010) reviewed the taxonomic history of M. cribraria and Megacopta punctatissima (Montandon) and indicated that the latter was considered to be a synonym of the former by Yang (1934). Both names continue to be used today, however, primarily in Japanese economic literature. We have examined specimens from Japan, China, and India and have been unable to find differences in morphology or genitalia. Specimens from the southeastern United States

32 are variable in size and specimens resembling published photos of both species occur in this area. Jenkins et al. (2010) found that molecular characters for Georgia specimens are similar to those previously reported for $M$. cribraria. So for the present, we refer to our specimens as $M$. cribraria until studies are conducted to clarify the species relationships. The close genetic link to specimens from Japan suggests that our species may be M. punctatissima should this species be found to be distinct from M. cribraria.

Prior to 2009, M. cribraria was known only from Asia (Eger et al. 2010). It was originally described as Cimex cribraria by Fabricius with specimens from India in 1798. It has since been reported from various locales throughout Asia and the Indian subcontinent (although the very

42 similar species M. punctatissima predominates in the main islands of Japan - Honshu, Shikoku, 43 and Kyushu (Tomokuni et al. 1993)). Megacopta cribraria is the only member of its family 44 (Plataspidae) in North or South America. However, a close relative, Coptosoma xanthogramma 
45 (White), was detected in Hawaii in 1965 (believed to originate in the Philippines) and has since established there as a pest of legumes (Beardsley and Fluker 1967). The family Plataspidae

47 belongs to the hemipteran superfamily Pentatomoidea (Schuh and Slater 1995), and outside of

48 the Plataspidae, the genus Megacopta appears to be most closely allied with the family

49 Scutelleridae and by further extension to the Pentatomidae (Schuh and Slater 1995; Li et al.

50 2005).

51

52 The origins of the M. cribraria established in the US are unclear. DNA was extracted from 269

53 individuals from across the spatial and temporal range of M. cribraria in the southeastern US.

54 Polymerase chain reaction (PCR) was then used to amplify and sequence a 2336 bp

55 mitochondrial fragment (Jenkins et al. 2010, Jenkins and Eaton 2011). All of these fragments

56 analyzed to date are the same. Only one female line, designated GA1 (Jenkins and Eaton 2011)

57 has been observed. While more lines may have been introduced, only one has so far been

58 found from random sampling using this marker. Thus, at least for mtDNA, there appears to be a

59 lack of genetic diversity in introduced $M$. cribraria, even as the bug rapidly moves into new

60 territory. Furthermore, preliminary data comparing GA1 haplotypes with haplotypes collected

61 from sites across Asia appear to indicate strong similarity with collections in Japan and South

62 Korea (Jenkins, unpubl. data).

63

64 Eger et al. (2010) provide an excellent overview of the life history of the insect, and their

65 information is summarized here, with additional information derived from various sources. The

66 common name applied to the bug in the region ("kudzu bug") derives from the insect's close 
67 association with kudzu, which is also noted in its original range in Asia. Circumstances in the southeastern US are ideal for M. cribraria, and unique for the US, in that kudzu, a perennial invasive weed pest native to Asia, is ubiquitous in the region, providing the bugs with their ideal host plant in abundance when they arrived. Kudzu bugs overwinter as adults clustered in sheltered areas (e.g., under loosened tree bark) in the vicinity of fall host plants (typically kudzu). Adults emerge from overwintering habitats in early spring and become very active, possibly looking for host plants and/or mates. The bugs are strong and rapid fliers and they become urban nuisances during the spring flight period in the US, especially in and around light-colored homes and structures. The large numbers of insects produced in kudzu (Zhang et al. 2012) and the strong flight ability of adults likely account for the rapid expansion of the kudzu bug's geographic range in the southeastern US, possibly aided by spring weather patterns producing active fronts that tend to move from west to east and northeast, corresponding with the most pronounced region of spread of the kudzu bug (Fig. 1).

Initial kudzu bug reproduction in the spring is synchronized with the emergence of buds in kudzu, the only perennial host known to support large numbers of $M$. cribraria, but eggs may be deposited on other potential host plants, such as wisteria (Wisteria sinensis (Sims)) and early-planted soybeans available at the same time, though not in the numbers observed on kudzu. Eggs are deposited largely on leaf nodes near the vine tips and, to a somewhat lesser extent, on bracts on kudzu vines, and on the undersides of kudzu leaves. An average of 16 eggs (Zhang et al. 2012) is deposited in two parallel rows, with fecal pellets containing symbionts placed beneath the egg mass. The symbionts play a key role in the dietary range of the bugs 
(Hosokawa et al. 2006). Eggs hatch in 3-7 days, depending on temperature. The nymphs pass through five instars over a period of about 4-6 weeks. Adult longevity has been variously estimated at 2-5 days (Srinivasaperumal et al. 1992), 7 days (Aiyar 1913), and 23-64 days (Thippeswamy and Rajagopal 2005) in the spring and summer. Zhang et al. (2012) reported second generation adult longevity of 6-25 days in Georgia depending on host plant. Those tests were conducted at outdoor temperatures in a shaded area in July, while J.R. Ruberson observed adult longevity of $21-43$ days in Georgia under laboratory conditions ( $25 \pm 1^{\circ} \mathrm{C}$; L:D $\left.14: 10\right)$ with snap bean pods (Phaseolus vulgaris L.) as food. Fecundity estimates are also rather wide: from 10-40 eggs (Aiyar 1913), 49-73 eggs (Srinivasaperumal et al. 1992), and 102-157 eggs (Thippeswamy and Rajagopal 2005) per female. Rearing conditions for these studies varied widely, confounding generalizations for the bugs currently in the US. For example, M. cribraria performed poorly in caged oviposition trials in Georgia (Zhang et al. 2012) suggesting that the bugs are sensitive to conditions that limit their movement or shade the plant.

After the first generation has completed development in kudzu or early-planted soybeans, many of the new adults move to other host plants, and can become serious pests of soybeans and other legumes. The second generation is passed in late summer primarily on kudzu (Zhang et al. 2012), soybeans (Greene et al. 2012) and some other legumes. The bugs appear to be bivoltine in the southeastern United States on kudzu (Zhang et al. 2012), which corresponds with phenology reported in China (2-3 generations annually: Li et al. 2001; Zhang and Yu 2005; Chen et al. 2009) and for M. punctatissima on kudzu in southern Japan (Takasu and Hirose 1986). Eggs on soybeans and other crop legumes are typically placed on stems and leaves, and 
111 hatched nymphs and adults feed chiefly on stems and, to a lesser extent, on leaves. Feeding on

112 fruiting structures is highly unusual. Damage to plants appears to be a result of stress inflicted

113 on the plant by high numbers of feeding bugs. Kudzu bugs can be rather non-discriminatory in

114 their oviposition habits, as they have been reported to lay eggs on peaches, pecans, metal

115 posts, plastic structures, and other plants and objects that are unlikely developmental hosts.

116 However, when given a choice, they preferentially oviposit on kudzu and to a lesser extent on

117 soybeans (Zhang et al. 2012). In that study, some eggs were also deposited on Lespedeza hirta

118 (L.) Hornem., L. cuneata (Dum. Cours.), Wisteria frutescens (L.), Vigna unguiculata (L.), Lablab

119 purpureus (L.), and Robinia pseudoacacia L., but development was only completed on kudzu

120 and soybeans.

121

122 The taxonomic range of the bug's developmental hosts is poorly known. Defining the host

123 range of $M$. cribraria is further complicated by the presence of gut symbionts that appear to

124 play a significant role in shaping host plant suitability (Hosokawa et al. 2006; 2007).

125 Srinivasaperumal et al. (1992) conducted a life table analysis for M. cribraria nymphs and adults

126 on the plants Sesbania grandiflora (L.) and Crossandra undulaefolia Salisb., as well as cotton,

127 Gossypium hirsutum L., and found that the bugs could develop successfully from egg hatch to

128 adult on all three species. However, developmental time was prolonged, and adult size and

129 fecundity were reduced for bugs that developed on cotton, suggesting that this is a less optimal

130 host. It must be noted that Srinivasaperumal et al. (1992) inoculated the respective plants with

131 M. cribraria eggs and did not observe oviposition on the tested plants. Thippeswamy and

132 Rajagopal (2005) evaluated the life history of M. cribraria on soybean, field bean (L. purpureus), 
133 and redgram (or pigeon pea, Cajanus cajan (L.)) and found that although the bugs could readily

134 oviposit and complete development on soybean and field bean, they failed to oviposit on

135 redgram, although they congregated, fed on, and seriously damaged the plants.

Urban Issues: Megacopta cribraria was first noticed in the US because it appeared en masse on homes and property in close proximity to kudzu in the fall of 2009 (Suiter et al. 2010). This problem has recurred each spring and fall in the region, as the bugs actively move in the spring in search of food and reproductive resources prior to significant kudzu growth in the spring, and as they search for overwintering sites in the fall. The insects are nuisance pests in the urban

142 environment, aggregating in great numbers on and around homes and other structures. The 143 bugs are attracted to light-colored vertical surfaces, which provides an effective means of 144 trapping them (Horn and Hanula 2011, Zhang et al. 2012), but also contributes to their aggregation on homes, other buildings, and vehicles, reinforcing their status as urban pests.

146 Because M. cribraria are active fliers, they not only annoy people in open areas, but also readily 147 enter homes and other buildings through open doors and windows. Annoyance can also be less 148 benign. Bugs (especially nymphs) crushed against the skin can induce rashes (Fig. 2), and can 149 stain surfaces when crushed against them. Risks of localized dermal rashes are likely minimal in and around structures, but these concerns are much greater for workers in soybeans or kudzu 151 where nymphs can be abundant.

153 Crop-related Issues: In Asia, M. cribraria tends to be an occasional pest of legumes, but can be 154 serious at times. Thippeswamy and Rajagopal (1998) found that yield of field bean ( $L$. 
155 purpureus) was reduced from 9-44\% by increasing infestations of the kudzu bug, and the yield

156 reduction was more pronounced when infestations occurred in the crop's vegetative stage than

157 in the reproductive stage. Similar results were observed in soybeans in China, where $0.5-50 \%$

158 yield loss was reported (Wang et al. 1996), and in Japan where clear density-dependent effects

159 on soybeans were documented (Kikuchi and Kobayashi 2010).

160

161 The very limited number of publications pertaining to this insect as a pest or to its management

162 indicates that M. cribraria is not a consistently significant crop problem in its native range. This

163 is not the case in the US, where bugs appear consistently in large numbers in soybean fields

164 within the southeastern range of the pest. This is most likely due to the large number of bugs

165 produced during the first generation in kudzu, which is abundant and widespread in the

166 southeastern US. Some portion of this very large first generation of adults then migrates from

167 kudzu to soybeans where the adults oviposit and their progeny complete development.

168 However, observations from spring of 2012 indicated that overwintered bugs moved directly to

169 early-planted soybeans (Phillip M. Roberts, University of Georgia, and Jeremy K. Greene,

170 Clemson University, unpubl. data), bypassing kudzu entirely, and suggested that the wild host

171 plant might not be necessary for the insect to propagate in a given region in the spring if

172 sufficient suitable alternative hosts are present.

173

174 Studies conducted in 19 soybean fields in Georgia and South Carolina in 2010 and 2011 showed

175 that kudzu bug populations reduced soybean yields in untreated fields from 0-47\% (16 of the 19

176 fields suffered yield loss), with an average loss of $18 \%$ (Greene et al. 2012). Therefore, at least 
177 one application of a broad-spectrum insecticide will likely be required to reduce damage in

178 infested soybeans in the US. An additional application of insecticide to soybeans would add a

179 cost of $\$ 15-22$ per hectare, as well as environmental costs of additional pesticides in the

180 environment. The best chemical controls for the pest in China were found to be broad-

181 spectrum insecticides, such as chlorpyrifos (Zhang and Yu 2005) and deltamethrin (Li et al.

182 2001), among others (Wu et al. 1992), all of which have significant non-target effects on the

183 environment. A number of organic growers in northern Georgia have had snap bean crops

184 severely damaged and, in some cases, destroyed by heavy populations of kudzu bugs

185 (Ruberson, unpubl. data). Organic growers have very limited therapeutic options to control the

186 insects. The economic losses of organic producers have not been calculated, but growers report

187 that they are significant. As this invasive species continues to expand its range in the US, its

188 adverse impact on soybeans and other cultivated legumes will continue to increase. However,

189 the magnitude of the pest problems and extent of the insect's spread may be limited by the

190 distribution and abundance of kudzu, because of the insect's close relationship with this host

191 plant.

192

193 International Issues: In December, 2011, two dead kudzu bug adults were recovered by

194 Honduran inspectors on the floor of a shipping container of fertile chicken eggs originating from

195 Georgia. On 11 February 2012, Honduran inspectors identified seven dead kudzu bug adults in a

196 containerized shipment of frozen chicken meat paste from Georgia. These interceptions

197 prompted Honduran officials to halt acceptance of any agricultural products shipped from

198 Alabama, Georgia, and South Carolina on 27 February 2012. Two days later, shipments from 
199 North Carolina were included in this action. Within 48 hours of this action, Honduran officials

200 accepted all shipments only after inspection of $100 \%$ of the containers.

201

202 The US Department of Agriculture Animal and Plant Health Inspection Service (USDA APHIS)

203 worked with the University of Georgia and industry partners to develop and implement a

204 standard operating protocol for loading containers to ensure freedom from kudzu bugs. The

205 protocol centered on exclusion practices in loading and handling areas, visual inspections, and

206 cleaning of containers before loading. The University of Georgia hosted representatives from

207 nine Central American member countries of the Organismo Internacional Regional de Sanidad

208 Agropecuaria (OIRSA) in April 2012 to provide current information about the bug, the risks it

209 poses, and management options (e.g., http://southeastfarmpress.com/markets/kudzu-bug-

210 now-interfering-southeast-exports?page=1; accessed 5 September 2012). Normal trade has

211 resumed, but Honduras and several other Central American governments inspect double the

212 number of shipping containers from countries/areas in which the kudzu bug is endemic than

213 from areas in which the insect does not occur. There remains great concern about M. cribraria

214 possibly invading and becoming established in Central America, and there is concern that these

215 worries will spread to other US trading partners in the Americas and elsewhere, especially

216 countries such as Brazil, with large acreages in soybeans and other legumes. These concerns are

217 underscored with the interception of kudzu bugs by Honduran and Guatemalan inspectors on

218 commercial passenger and cargo airlines originating from Atlanta, Georgia, and other

219 international airports in infested areas.

220 
221 Beneficial Aspects: Although M. cribraria is a crop and urban pest in the southeastern US where

222 kudzu occurs, the bugs are also having a beneficial effect by reducing kudzu growth. Zhang et

223 al. (2012) found that the bugs feeding in kudzu led to a total biomass reduction of $32.5 \%$ during

224 the first year of infestation, demonstrating that the bug can have a significant adverse effect on

225 kudzu at the current high population levels found during initial invasion in a new area. Kudzu is

226 considered one of the most serious invasive plants in regions where it occurs (Fig. 3), where it

227 has been estimated to cover approximately 2.8 million ha (Blaustein 2001) and continues to

228 expand. Grebner et al. (2011) estimated that recovering land infested by kudzu and planting it

229 with pine trees could result in increased land expectation values of $\$ 3-4,000 /$ ha at the end of a

23030 -year rotation, depending on the treatment methods used to eradicate kudzu. Effective

231 biological control of kudzu would increase that value significantly by reducing or eliminating

232 kudzu control costs. Importation biological control efforts have been directed at kudzu, but no

233 releases have been made because of the generalized feeding range of kudzu herbivores that

234 could lead to significant nontarget effects, most notably with soybeans, which are closely

235 related to kudzu (Frye et al. 2007). Megacopta cribraria feeds on kudzu stems and most likely

236 reduces the plant's capacity for growth by stressing the plant. Given the ability of the bug to

237 disperse and locate patches of kudzu, there is potential for the insect to have a significant effect

238 on scattered kudzu patches across many habitat types.

\section{SPREAD OF THe KudZu Bug}

241 It is anticipated that the problems and benefits delineated above will spread along with the

242 kudzu bugs. Their movement from initial infestation areas has been rapid. Initially found in nine 
243 counties in northern Georgia in 2009, the kudzu bug has moved rapidly to cover a much larger

244 area of the southeastern US (see Fig. 1). Also in 2010, the first reports of the kudzu bug

245 attacking soybeans were recorded in Georgia and South Carolina. More widespread complaints

246 about the bug in urban areas of northern Georgia were received in fall of 2010.

247

248 In 2011, the bug continued to move rapidly and was eventually reported in every county in

249 South Carolina, numerous counties in North Carolina, and in Virginia (Fig. 1). In 2012, the insect

250 has continued to spread, with bugs found in Florida and Tennessee, and throughout nearly all

251 of Georgia.

252

253 Management

254 The serious economic and social concerns related to the kudzu bug justify efforts to suppress its 255 populations in a variety of environments and over large areas. Data generated thus far indicate

256 that broad-spectrum insecticides (organophosphates and pyrethroids) are effective against the

257 bugs (e.g., Wang et al. 2004, Greene et al. 2012), but in sensitive areas, such as urban

258 neighborhoods where kudzu is abundant, more environmentally benign approaches are

259 needed, such as biological control. We address this topic below, focusing on natural enemies

260 native to North America and then on enemies in the original range of the pest and their

261 potential for use in classical biological control programs directed against the insect.

262

263 Role of Native Natural Enemies. Native natural enemies in North America have not yet

264 demonstrated the capacity to significantly reduce populations of $M$. cribraria, based on the 
persistently large populations of the bugs present in kudzu and infested soybeans in epicenter areas three years after the infestations were first observed. Some native predators have been found to feed on adults and nymphs of M. cribraria in the laboratory and/or field (see Table 1). The predators Geocoris uliginosus (Say), Zelus sp., Hippodamia convergens Guérin-Méneville, and Chrysoperla rufilabris (Burmeister) have been observed feeding on nymphs in kudzu in the field (Table 1), offering promise of growing activity of native predators. The predatory pentatomid Euthyrhynchus floridanus (L.) was also observed attacking adult M. cribraria on beans, Phaseolus vulgaris L., in the garden of an organic grower (Cyndi Ball, in northern Georgia). The impact of these predators is presently unknown in kudzu or any other host plant, but all are generalists, as would be expected given the lack of Plataspids in the Americas, and these predators may have limited impact on the bug populations.

No egg parasitoids have been found to date in samples in Georgia. In 2010, 287 egg masses from four counties in northern Georgia (Burke, Clarke, Elbert, and Morgan) were collected by Ruberson, and none of them yielded parasitoids. Likewise, Zhang et al. (2012) placed all egg masses from their weekly samples of kudzu vines in rearing and found no egg parasitoids. In 2011, Ruberson collected 345 egg masses from five counties in northern and eastern Georgia(Bulloch, Burke, Clarke, Jasper, and Morgan), and no egg parasitoids were found. Laboratory evaluations conducted by Walker Jones (USDA-ARS) with several native egg parasitoids also suggest that native egg parasitoids may not readily accept $M$. cribraria eggs. Because M. cribraria is the sole member of the Family Plataspidae present in North America (Eger et al. 2010), there may be difficulties for egg parasitoids in North America to successfully 
287 parasitize the bug's eggs. Inability of extant egg parasitoids to successfully parasitize $M$.

288 cribraria eggs is further supported by quarantine studies by Walker Jones in which M. cribraria

289 eggs were exposed to several important egg parasitoids of Pentatomidae present in North

290 America, including Trissolcus basalis (Wollaston) (Hymenoptera: Platygastridae (= Scelionidae)),

291 which exhibits a very broad host range within the Pentatomidae (Johnson 1985). None of the

292 parasitoids attacked eggs of $M$. cribraria or showed interest in them, suggesting that specific

293 cues for the parasitoids may be lacking. Therefore, parasitism of eggs by extant species does

294 not appear to be likely, at least in the near-term.

295

296 A single tachinid parasitoid was recently obtained from an adult M. cribraria collected on 2 April

2972012 in Tifton, Tift County, Georgia by M. D. Toews. This is the first case of adult parasitism

298 observed in hundreds of bugs collected and held, so it may represent a rare event, or the

299 beginning of a novel relationship. The specimen was determined to be Phasia robertsonii

300 (Townsend) by Dr. Norman Woodley (Systematic Entomology Laboratory, Smithsonian

301 Institution). This native parasitoid has been reared from adult Miridae and Pentatomidae

302 (Arnaud 1978; as Alophorella pulverea (Coquillet)), so it has a broad host range. No other

303 parasitoids have been observed from eggs, nymphs or adults.

304

305 A single specimen of $M$. cribraria was found infected with the entomopathogenic fungus

306 Beauveria bassiana (Balsamo) Vuillemin in kudzu in Georgia in 2010 (Zhang and Gardner,

307 unpubl, data) and in soybeans in Tift County, Georgia in 2012 by Ruberson. No other pathogens

308 have been observed. 
Classical Biological Control Opportunities. There is relatively limited information about natural enemies of $M$. cribraria in its native range, perhaps due to its limited pest status in these regions. Among natural enemies in the bug's native range, there is particularly little information on predators and pathogens. Only three cases of predation have been recorded. In the first case, Ahmad and Moizuddin (1976) noted that fifth instars and adults of $M$. cribraria were 315 attacked by Reduviids (identified as "Reduviius [sic] sp.") on lablab in Karachi, Pakistan, but that 316 smaller nymphs were not attacked. They provided no quantitative or other data regarding the 317 importance of the Reduviids, other than concluding that "Predators appear to have less 318 importance [than egg parasitoids] in biological control programme" (p. 86). The second and 319 third cases of predation were reported by Borah and Sarma (2009a), and are field observations 320 of predation by a spider (the Oxyopid Oxyopes shweta Tikader) and a predatory bug (the 321 Pyrrhocorid Antilochus coqueberti (F.)). Populations of the spider correlated positively and 322 significantly with those of $M$. cribraria, whereas populations of the predatory bug were too low 323 to assess. There are several reports of coccinellid predators of other Plataspids having 324 significant effects on plataspid populations and exhibiting some prey specificity (see summary 325 in Dejean et al. 2002). There are no such reports, however, for M. cribraria.

327 Only a single pathogen has been reported attacking $M$. cribraria in its native range. Borah and 328 Dutta (2002) reported natural infections of $M$. cribrarium (= M. cribraria) nymphs and adults in 329 Assam, India, by the entomopathogenic fungus B. bassiana. They verified pathogenicity by 
330 fulfilling Koch's postulates on bugs (Borah and Dutta 2002; Borah and Sarma 2009b). Levels of

331 infection were 31\% in November 1997 and 19\% in November 1998.

332

333 The bulk of the available information on natural enemies in the native range is focused on egg

334 parasitoids. This bias may reflect the ease of sampling and of making observations rather than

335 the actual relative importance of natural enemy guilds or taxa. However, no nymphal or adult

336 parasitoids have been reported in the literature, suggesting that such enemies may be rare or

337 non-existent in the native distribution.

338

339 Among egg parasitoids, the Platygastridae and Encyrtidae are the most important, although

340 Aphelinidae have also been reported. For example, the aphelinid parasitoid Encarsiella

341 (=Dirphys) boswelli (Girault) has a southern Australasian and tropical Indian and African

342 distribution, and has been reared from the plataspids Brachyplatys vahlii (F.) in Malaysia, $M$.

343 cribraria in India, and Coptosoma/Brachyplatys sp. in Zaire (Polaszek and Hayat 1990; 1992).

344 However, there are no data regarding rates of parasitism by this species in the field, and the

345 species appears to be uncommon, based on Megacopta parasitoid surveys in India, China, and

346 elsewhere.

347

348 More common are the Platygastrids and Encyrtids, which are commonly observed attacking

349 eggs of M. cribraria within the bug's native range. In China, Zhang et al. (2003) observed

350 parasitism of $M$. cribraria eggs in soybeans by the Encyrtid Ooencyrtus sp. and the Platygastrid

351 Trissolcus sp. (possibly Paratelenomus saccharalis (Dodd)), with Ooencyrtus sp. dominating 
352 parasitism of eggs of the initial bug generation in soybeans (accounting for $61 \%$ of parasitism in 353 Jiangsu Province). Wu et al. (2006) observed both Ooencyrtus nezarae Ishii and $P$. saccharalis 354 (as Asolcus minor) parasitizing eggs of M. cribraria in Fuzhou, China, from May to October in 355 soybeans. As was the case with Zhang et al. (2003), O. nezarae was the dominant parasitoid 356 reported by Wu et al. (2006), and overall egg parasitism levels ranged from 22.4 to $76.9 \%$. Wall $357(1928 ; 1931)$ observed parasitism of M. cribraria eggs (and two other plataspid species) in 358 Guangdong Province, China, by $P$. saccharalis in cultivated beans from late June to mid-August, 359 accounting for about $51 \%$ parasitism of all eggs collected. Although 0 . nezarae can exhibit high 360 parasitism rates, it is a generalist parasitoid of heteropteran eggs - attacking Plataspidae,

361 Pentatomidae, and Alydidae - and is also a facultative hyperparasitoid (Takasu and Hirose 362 1991).

364 Egg parasitism for M. punctatissima in Japan can be quite high (43-100\%), with parasitism by $P$. 365 saccharalis dominating early in the season and $O$. nezarae becoming the dominant parasitoid 366 later in the season (Takasu and Hirose 1986). Ahmad and Moizuddin (1976) reported a species 367 of Trissolcus attacking eggs of $M$. cribraria in Pakistan, but provided no information on rates of 368 parasitism in the field. Srinivasaperumal et al. (1992) conducted a life table analysis on S. 369 grandiflora, C. undulaefolia, and cotton and observed parasitism of artificially placed eggs on all 370 three crops, ranging from 4.3 to $20.6 \%$ from May to July in southern India. All egg parasitism 371 was attributed to P. saccharalis (as Archiphanurus). 
373 The parasitoid selected for proposed releases in the US is $P$. saccharalis for three reasons. First,

374 its ecology has been studied in Japan, so there is a good body of knowledge already in place.

375 Second, the parasitoid appears to be highly host specific, with the only known hosts being

376 several species in the family Plataspidae. Third, the parasitoid has a wide geographic

377 distribution in the Eastern Hemisphere, which should facilitate locating a strain or strains that

378 is/are adapted to climatic conditions in the invaded region. We overview each of these issues

379 below.

380

381 Paratelenomus saccharalis Ecology. As noted above, P. saccharalis has been recorded

382 parasitizing eggs of Megacopta/Coptosoma species in various studies throughout Asia. Studies

383 in Japan and elsewhere have demonstrated a close spatial and temporal synchrony between

384 the parasitoid and its host. Paratelenomus saccharalis is a primary and solitary endoparasitoid

385 of eggs of M. cribraria and M. punctatissima in Asia (Johnson 1996). Parasitism rates in the

386 spring are relatively high (up to $80 \%$ ), but rates in late summer are much reduced, possibly due

387 to facultative hyperparasitism by the competing egg parasitoid $O$. nezarae (Takasu and Hirose

388 1991).

389

390 Parasitoid developmental time from oviposition to adult emergence varied from $11.7 \pm 1.03 \mathrm{~d}$

391 at $30^{\circ} \mathrm{C}$ to $24.8 \pm 0.66 \mathrm{~d}$ at $20^{\circ} \mathrm{C}$ for a parasitoid population from Fukuoka, Japan, with an

392 estimated thermal requirement of 208.3 degree days (base $12^{\circ} \mathrm{C}$ ) (Takagi and Murakami 1997).

393 Survival across these same temperatures ranged from $58.6 \%$ at $30^{\circ} \mathrm{C}$ to $96 \%$ at $20^{\circ} \mathrm{C}$. Takagi and

394 Murakami (1997) also calculated the lower developmental threshold to be $11.8^{\circ} \mathrm{C}$, and 
estimated a thermal requirement of 208.3 degree days (base $12^{\circ} \mathrm{C}$ ) from egg to adult emergence. On this basis, they estimated that approximately four generations of the parasitoid could occur from 1 July to 31 August in the region of Fukuoka, Japan.

Wall (1928) noted that parasitoids were most successful parasitizing young eggs (“...it is only in the last third of the embryonic development of the host... that the parasitoid is unable to parasitize the host egg"; p. 234). An inverse relationship between host age and suitability is typical for egg parasitoids (e.g., Pak 1986).

Takasu and Hirose (1986) found that parasitism of M. punctatissima eggs by $P$. saccharalis (as $A$. minor) increased quickly after bug oviposition began in kudzu (end of May) in Fukuoka, Japan, and within two weeks reached levels of 57-81\% from mid-June through early July, when the parasitoid $O$. nezarae became more prevalent. Similarly, the parasitoid was found in close temporal association with C. cribrarium (=M. cribraria) in the spring in India (Rajmohan and Narendran 2001). There may be differences in parasitoid efficacy among host plants. Takasu and Hirose (1985) reported that eggs of $M$. punctatissima were only parasitized by $O$. nezarae in soybeans, although P. saccharalis occurred in the same area. Similarly, Hirose et al. (1996) noted little parasitism of M. punctatissima by P. saccharalis (as Paratelenomus minor) in soybeans, but the very high levels of parasitism by $O$. nezarae in soybeans, coupled with the comparable numbers of adult females of the two parasitoid species trapped in the crop, may indicate that $O$. nezarae is able to outcompete $P$. saccharalis. 
417 Although P. saccharalis is bisexual throughout its Australasian and Asian range, Bin and Colazza

418 (1986) reported that the population found in Italy was thelytokous, was active in July and

419 August, and that parasitism ranged from 4.5 to $34.2 \%$ during this period (averaged over three

420 years).

421

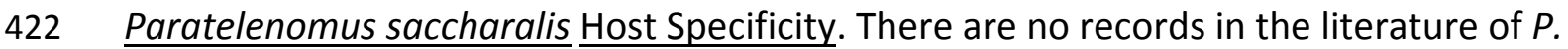

423 saccharalis being reared from any hosts besides selected plataspid species (e.g., Johnson 1996).

424 Johnson (1996) reported the parasitoid's known hosts from museum specimens and the

425 literature as the Plataspids Brachyplatys subaeneus Westwood in China (citing Wall 1928;

426 1931), Megacopta (=Coptosoma) cribrarium (F.) in China, and M. punctatissimum in Japan. Bin

427 and Colazza (1986) reported rearing the parasitoid (identified as Archiphanurus graeffei

428 (Kieffer)) from the sole known Italian Plataspid, Coptosoma scutellatum (Geoffroy), on a wild

429 legume host (Ononis spinosa L.). Hirose et al. (1996) collected egg masses of four species of

430 hemipterans in soybeans, but $P$. saccharalis was reared only from eggs of $M$. punctatissimum, in

431 stark contrast with 0 . nezarae, which was reared from eggs of all four species. The lack of

432 records for any hosts besides Plataspids suggests that the parasitoids may be restricted to hosts

433 in this bug family. There are no known plataspid species in the Americas; therefore, there is a

434 significant phylogenetic gap between M. cribraria and other Pentatomoids present in North

435 America that may also be reflected in the host range of the parasitoid. Evaluations of the

436 parasitoid to date in quarantine in the US further indicate the parasitoid has no interest in a

437 variety of pentatomoid and other Hemipterans found in North America. The lack of any

438 successful parasitism in quarantine studies supports the literature on specificity. 
$440 \quad$ Paratelenomus saccharalis Geographic Distribution. The parasitoid $P$. saccharalis is widely 441 distributed throughout the Eastern Hemisphere. The Geographic Biodiversity Information

442 Biofacility (GBIF) provides 275 georeferenced records for the parasitoid

443 (http://es.mirror.gbif.org/species/16198853, accessed 1 May 2012) demonstrating the wide 444 geographic distribution of the parasitoid based on museum specimens. The parasitoid has been 445 collected throughout the Australasian region, India, and Western and Central Europe. It has also 446 been collected in the Middle East and Africa. This distribution corresponds with that of 447 members of the Family Plataspidae.

\section{CONCLUSIONS}

450 The kudzu bug or bean plataspid, Megacopta cribraria, is rapidly spreading in the southeastern 451 United States, where it is closely associated with kudzu, but can also infest soybeans and some 452 other legumes. In addition to causing economic damage to soybeans, the bugs have become a 453 considerable nuisance in urban landscapes where kudzu occurs. The insect has a remarkable 454 capacity for movement and has spread from nine Georgia counties in 2009 to seven states in 455 2012. Although a nuisance in urban areas and a crop pest, the bug also reduces biomass of 456 kudzu, which is itself a seriously problematic invasive weed, complicating the status of $M$. 457 cribraria in its expanded range. Native natural enemies have been observed attacking kudzu 458 bugs in the laboratory and field, and might eventually reduce their populations, but at present 459 native enemies appear to be insufficient for the task. Therefore, exotic enemies from the kudzu 460 bug's native range may offer the best possibility for effective biological control in the US. Based 
461 on available literature, the best option for an importation biological control program appears to

462 be the platygastrid egg parasitoid Paratelenomus saccharalis because of its apparent host

463 specificity, intimate biological linkages with M. cribraria, and wide geographic distribution in

464 the Eastern Hemisphere. Other natural enemies may eventually emerge as good candidates for

465 importation, but at present $P$. saccharalis appears to be the most promising.

466

467

\section{ACKNOWLEDGMENTS}

468 We appreciate the careful review of the manuscript by Dr. James Hanula (USDA Forest Service, 469 Athens GA). 
472 Ahmad I, Moizuddin M (1976) Biological control measures of bean plataspids (Heteroptera: Pentatomoidea) in Pakistan. Proc Entomol Soc Karachi Volume unknown (6): 85-86

Aiyar TVR (1913) On the life history of Coptosoma cribraria, Fabr. Journal, Bombay Natural History Society 22: 412-414

Arnaud PH, Jr (1978) A host-parasite catalog of North American Tachinidae (Diptera). Misc Publ. 1319. USDA Science and Education Administration, Washington DC

Beardsley JW, Jr, Fluker S (1967) Coptosoma xanthogramma (White), (Hemiptera: Plataspidae) a new pest of legumes in Hawaii. Proc Haw Entomol Soc 19: 367-372

Bin F, Colazza S (1986) Egg parasitoids, Hym. Scelionidae and Encyrtidae, associated with Hemiptera Plataspidae. In: Trichogramma and Other Egg Parasites, $2^{\text {nd }}$ Internatl. Symp., Guangzhou, China. Ed. INRA, Paris, 1988

Blaustein RJ (2001) Kudzu's invasion into Southern United States life and culture. In: McNeeley, JA (ed.) The Great Reshuffling: Human Dimensions of Invasive Species. IUCN, Switzerland and Cambridge, UK, The World Conservation Union, pp 55-62.

Borah BK, Dutta SK (2002) Entomogenous fungus, Beauveria bassiana (Balsamo) Vuillemin: a natural biocontrol agent against Megacopta cribrarium (Fab.). Insect Environ 8:7-8 pigeonpea. Insect Environ 14:147-149 
490

491

492

493

494

495

496

497

498

499

500

501

502

503

504

505

506

507

508

509

510

511

Borah BK, Sarma KK (2009b) Pathogenicity of entomopathogenous fungus, Beauveria bassiana (Balsamo) Vuillemin on Megacopta cribrarium (Fab.): a sucking pest of pigeonpea. Insect Environ 14:159-160

Chen Q, Wang JL, Guo SJ, Bai HX, Zhuo XN (2009) Studies on the biological characteristics of Megacopta cribraria (Fabricius). J Henan Agr Sci 4:88-90

Dejean A, Orivel J, Gibernau M (2002) Specialized predation on plataspid heteropterans in a coccinellid beetle: adaptive behavior and responses of prey attended or not by ants. Behav Ecol 13:154-159

Eger JE, Jr, Ames LM, Suiter DR, Jenkins TM, Rider DA, Halbert SE (2010) Occurrence of the Old World bug Megacopta cribraria (Fabricius) (Heteroptera: Plataspidae) in Georgia: a serious home invader and potential legume pest. Insecta Mundi 0121: 1-11

Frye MJ, Hough-Goldstein J, Sun J-H (2007) Biology and preliminary host range assessment of two potential kudzu biological control agents. Environ Entomol 36:1430-1440

Grebner DL, Ezell AW,Prevost JD, Gaddis DA (2011) Kudzu control and impact on monetary returns to non-industrial private landowners in Mississippi. J Sustain For 30:204-223

Greene JK, Roberts PM, Gardner WA, Reay-Jones F, Seiter N (2012) Kudzu Bug Identification and Control in Soybeans. United Soybean Board, Chesterfield, MO. 10 pages

Hirose Y, Takasu K, Takagi, M (1996) Egg parasitoids of phytophagous bugs in soybean: mobile natural enemies as naturally occurring biological control agents of mobile pests. Biol Contr 7:84-94

Horn S, Hanula JL (2011) Influence of trap color on collection of the recently-introduced bean plataspid, Megacopta cribraria (Hemiptera: Plataspidae). J Entomol Sci 46:85-87 
512 Hosokawa T, Kikuchi Y, Nikoh N, Shimada M, Fukatsu T (2006) Strict host-symbiont cospeciation 513 and reductive genome evolution in insect gut bacteria. PLoS Biol 4:1841-1851

514 Hosokawa T, Kikuchi Y, Shimada M, Fukatsu T (2007) Obligate symbionts involved in pest status

515 of host insect. Proc Royal Soc B: Biol Sci 274:1979-1984

516 Jenkins TM, Suiter D, Eger J, Ames L, Buntin D, Eaton T (2010) The preliminary genetics of an

517 invasive true bug from the Old World: implications for the New World. J Entomol Sci 45:1-2

518 Jenkins TM, Eaton TD (2011) Population genetic baseline of the first plataspid stink bug

519 symbiosis (Hemiptera: Heteroptera: Plataspidae) reported ij North America. Insects 2:264-

$520 \quad 272$

521 Johnson NF (1985) Systematics of New World Trissolcus (Hymenoptera: Scelionidae) species

$522 \quad$ related to T. basalis. Can Entomol 117:431-45

523 Johnson NF (1996) Revision of World species of Paratelenomus Dodd (Hymenoptera:

$524 \quad$ Scelionidae). Can Entomol 128:273-291

525 Kikuchi A, Kobayashi H (2010) Effect of Injury by Adult Megacopta punctatissima (Montandon)

526 (Hemiptera: Plataspidae) on the Growth of Soybean during the Vegetative Stage of

527 Growth. Jpn J Appl Entomol Zool 54:37-43 (in Japanese with English summary)

528 Li H-M, Deng R-Q, Wang J-W, Chen Z-Y, Jia F-L, Wang XZ (2005) A preliminary phylogeny of the

529 Pentatomomorpha (Hemiptera: Heteroptera) based on nuclear 18s rDNA and

$530 \quad$ mitochondrial DNA sequences. Mol Phylog Evol 37:313-326

531 Li YH, Pan ZS, Zhang JP, Li WS (2001) Observation of biology and behavior of Megacopta

532 cribraria (Fabricius). Plant Prot Technol Ext 21(7): 11-12 (in Chinese) 
533 Pak, GA (1986) Behavioural variations among strains of Trichogramma spp. A review of the 534 literature on host-age selection. J Appl Entomol 101:55-64

535 Polaszek A, Hayat M (1990) Dirphys boswelli (Hymenoptera: Aphelinidae) an egg parasitoid of $536 \quad$ Plataspidae (Heteroptera). J Nat Hist 24:1-5

537 Polaszek A, Hayat M (1992) A revision of the genera Dirphys Howard and Encarsiella Hayat 538 (Hymenoptera: Aphelinidae). Syst Entomol 17:181-197

539 Rajmohan K, Narendran TC (2001). Parasitoid complex of Coptosoma cribrarium (Fabricius) $540 \quad$ (Plataspididae [sic]: Hemiptera). Insect Environ 6:163

541 Schuh RT, Slater JA (1995). True bugs of the world. Cornell University Press, Ithaca, NY.

542 Srinivasaperumal S, Samuthiravelu P, Muthukrishnan J (1992) Host plant preference and life 543 tale of Megacopta cribraria (Fab.) (Hemiptera: Plataspidae). Proc Indian Nat Science Acad 544 B58 (6):333-340

545 Suiter DR, Eger JE Jr., Gardner WA, Kemerait RC, All JN, Roberts PM, Greene JK, Ames LM, 546 Buntin GD, Jenkins TM, Douce GK (2010) Discovery and distribution of Megacopta cribraria 547 (Hemiptera: Heteroptera: Plataspidae) in northeast Georgia. J Integrat Pest Manag 1(1): 1548 4

549 Takagi M, Murakami K (1997) Effect of temperature on development of Paratelenomus saccharalis (Hymenoptera: Scelionidae), an egg parasitoid of Megacopta punctatissimum 551 (Hemiptera: Plataspidae). Appl Entomol Zool 32:659-660

552 Takasu K, Hirose Y (1985). Seasonal egg parasitism of phytophagous stink bugs in a soybean 553 field in Fukuoka. Proc Assoc Plant Prot Kyushu 31: 127-131 (in Japanese with English 554 summary) 
555 Takasu K, Hirose Y (1986). Kudzu-vine community as a breeding site of Ooencyrtus nezarae Ishii

556 (Hymenoptera: Encyrtidae), an egg parasitoid of bugs attacking soybean. Jpn J Appl

$557 \quad$ Entomol Zool 30:302-304 (In Japanese with English summary)

558 Takasu K, Hirose Y (1991) The parasitoid Ooencyrtus nezarae (Hymenoptera: Encyrtidae) prefers

559 hosts parasitized by conspecifics over unparasitized hosts. Oecologia 87:319-323

560 Thippeswamy C, Rajagopal BK (1998) Assessment of losses caused by the lablab bug,

561 Coptosoma cribraria Fabricius (Heteroptera: Plataspidae) to the field bean, Lablab

562 purpureus var. lignosus Medikus. Karnataka J Agric Sci 11:941-946

563 Thippeswamy C, Rajagopal BK (2005) Life history of lablab bug, Coptosoma cribraria Fabricius

564 (Heteroptera: Plataspidae) on field bean, Lablab purpureus var. lignosus Medikus.

565 Karnataka J Agric Sci 18:39-43

566

Tomokuni M, Yasunaga T, Takai M, Yamashita I, Kawamura M, Kawasawa T (1993) A field guide

567 to Japanese bugs.-Terrestrial Heteropterans. Zenkoku Noson Kyikyu Kyokai Publishing Co.,

568 Ltd., Tokyo, Japan

569

Wall RE (1928) A comparative study of a chalcid egg parasite in three species of Plataspidinae.

570 Lingnan Sci J 6:231-239

571 Wall RE (1931) Dissolcus tetartus Crawford, a scelionid egg parasite of Plataspidinae in China. Lingnan Sci J 9:381-382

573 Wang HS, Zhang CS, Yu DP (2004) Preliminary studies on occurrence and control technology of $574 \quad$ Megacopta cribraria (Fabricius). China Plant Prot 24(8):45 (in Chinese)

575 Wang ZX, Wang HD, Chen GH (1996) Occurrence and control of Megacopta cribraria (Fabricius) $576 \quad$ on soybean. Plant Prot 1996: 7-9 
577 Wu MX, Wu Z-Q, Hua S-M (2006) A preliminary study of some biological characters of globular 578 stink bug, Megacopta cribraria and its two egg parasitoids. J Fujian Agric For Univ (Natural $579 \quad$ Science Edition) 35:147-50

580 Wu YQ, Zhang XM, Hua AQ, Chen JF (1992) Observation of the biological characteristics and $581 \quad$ control of Megacopta cribraria (Fabricius). Insect Knowl 29:272-274

582 Zhang CS, Yu DP (2005) Occurrence and control of Megacopta cribraria (Fabricius). Chinese $583 \quad$ Countryside Well-off Technol 1:35

584 Zhang Y, Hanula JL, Horn S (2012) The biology and preliminary host range of Megacopta $585 \quad$ cribraria (Heteroptera: Plataspidae) and its impact on kudzu growth. Environ Entomol $586 \quad 41: 40-50$

587 Zhang Y-T, Du X-G, Dong M, Shei W (2003) A preliminary investigation of egg parasitoids of 588 Megacopta cribraria in soybean fields. Entomol Knowl 40:443-445 (In Chinese) 
591 Table 1. Predators observed feeding on M. cribraria in Georgia (observations by Ruberson,

592 Eger, Olson, Cyndi Ball; 2010 to 2012)

\begin{tabular}{llcc}
\hline \multicolumn{1}{c}{ Species } & Family & Stage attacked & Where observed \\
\hline Euthyrhynchus floridanus adult & Pentatomidae & Adult & Field \\
Nabis roseipennis (Reuter) adult & Nabidae & Nymph & Lab \\
Geocoris uliginosus adult & Geocoridae & Nymph & Lab, Field \\
Geocoris punctipes adult & Geocoridae & Nymph & Lab \\
Zelus sp. adult & Reduviidae & Nymph & Field \\
Sinea sp. adult & Reduviidae & Nymph, adult & Lab \\
Hippodamia convergens adult & Coccinellidae & Nymph & Lab, Field \\
Hippodamia convergens larva & Coccinellidae & Nymph & Lab \\
Chrysoperla rufilabris larva & Chrysopidae & Nymph & Lab, Field \\
\hline
\end{tabular}


595

596

597

598

599

600

601

602

603

604

605

606

607

608

609

610

\section{Figure Captions}

Fig. 1. Distribution and spread of Megacopta cribraria from 2009-2012 in the southeastern United States (prepared by Wayne A. Gardner, University of Georgia; July 2012).

Fig. 2. Dermatitis induced by nymphal M. cribraria being crushed between boots and socks while working in infested soybeans (photo courtesy of Michael D. Toews, University of Georgia).

Fig. 3. Documented distribution of kudzu, Pueraria montana var. lobata, in the United States, September 2012. Map produced by EDDMapS, 2012. Early Detection \& Distribution Mapping

System. The University of Georgia - Center for Invasive Species and Ecosystem Health. Available online at http://www.eddmaps.org/distribution/uscounty.cfm?sub=2425; last accessed September 20, 2012. 
611 Fig. 1

612

613

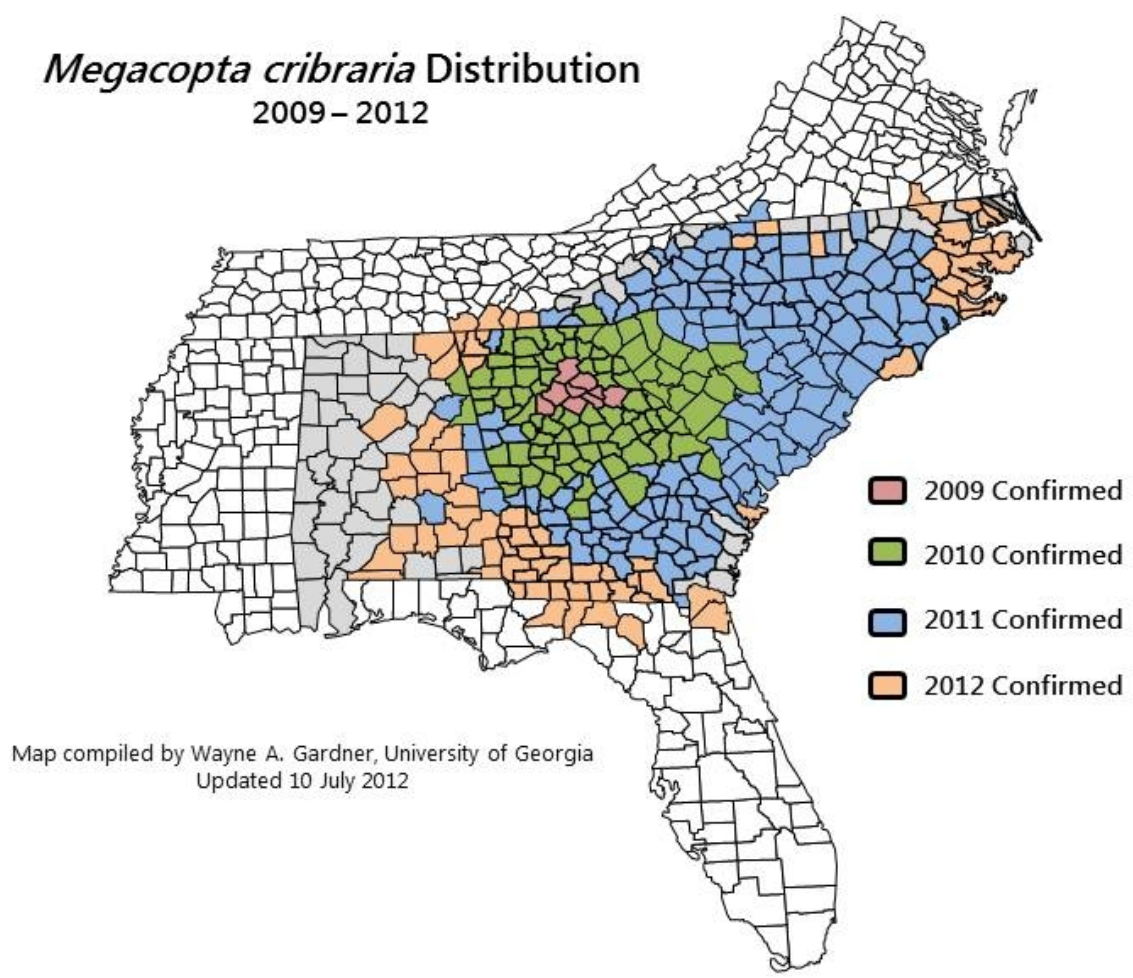

614

615 
616

617 Fig. 2

618

619

620

621

622

623

624

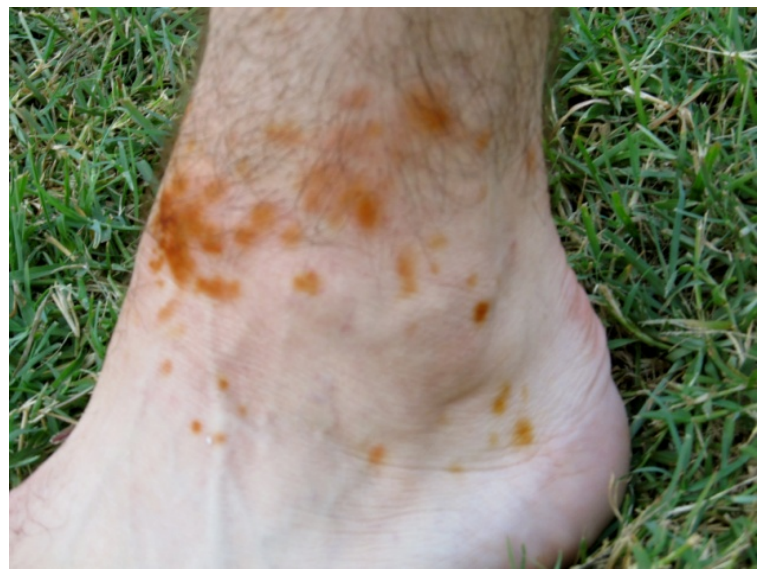

625 
Fig. 3.

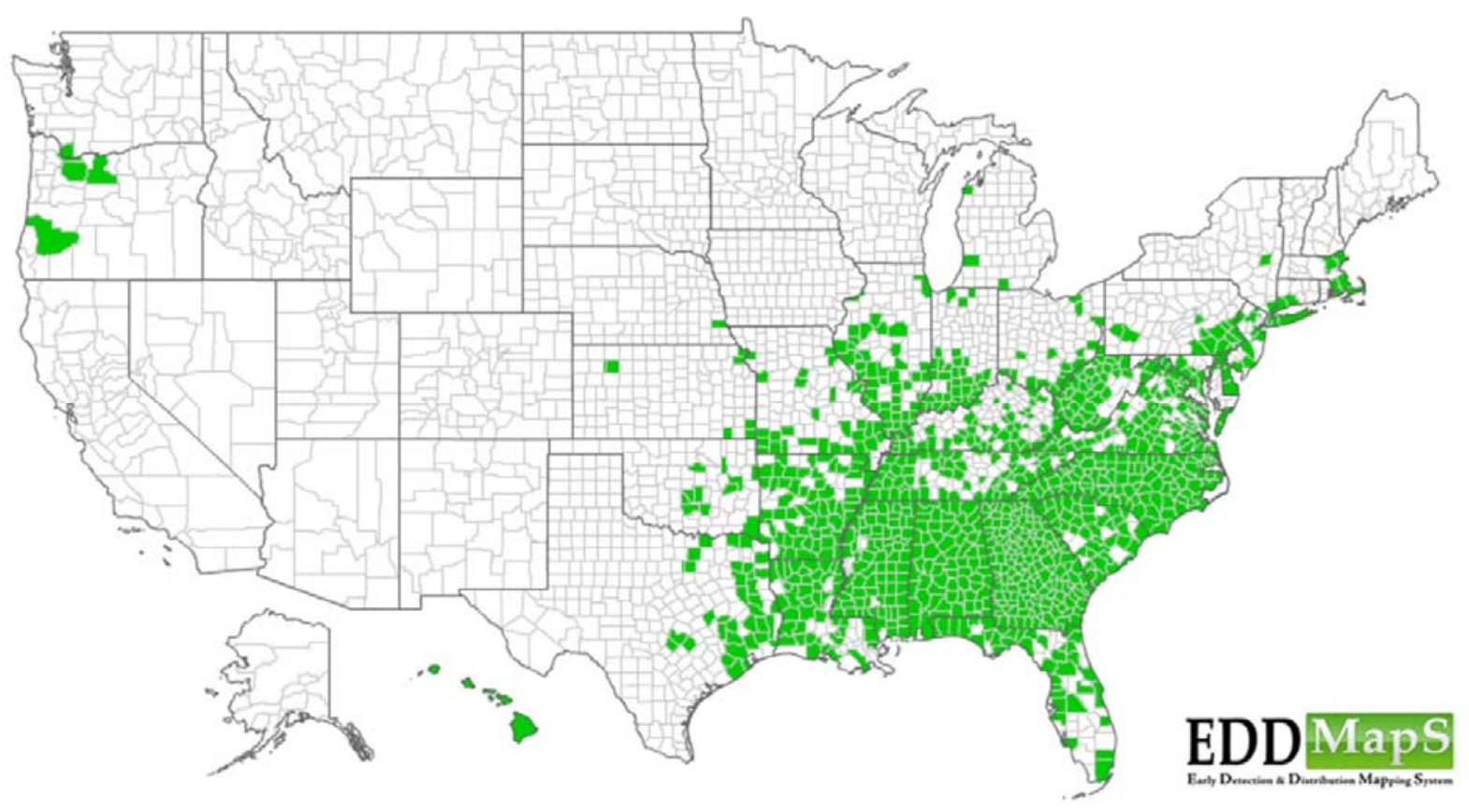

627

628 